\title{
EVALUASI PENYIMPANAN DAN PENDISTRIBUSIAN OBAT DI INSTALASI FARMASI RSUD NOONGAN, KABUPATEN MINAHASA PROVINSI SULAWESI UTARA
}

\author{
Tiarma $^{1)}$, Gayatri Citraningtyas ${ }^{1)}$, Paulina Yamlean ${ }^{1)}$ \\ ${ }^{1)}$ Program Studi Farmasi FMIPA UNSRAT Manado, 95115
}

\begin{abstract}
Drug management is one aspect of hospital management that is very important in providing overall health services because the inefficiency and ineffectiveness of drug management will have a negative impact on hospitals both medically, socially and economically. This study aims to evaluate the storage and distribution of drugs in accordance with the Regulation of the Minister of Health No. 72 of 2016 in Pharmacy Installation of Noongan District Hospital using a descriptive method with a retrospective and prospective approach. The results showed that the drug storage system in the Pharmacy Installation of Noongan General Hospital as a whole was not in accordance with the Regulation of the Minister of Health No. 72 of 2016 such as, warehouses that are not too large to store all drug supplies, the absence of regulators of humidity, the absence of pedestal boards and drugs placed directly on the floor, while the process of drug distribution is in accordance with Minister of Health Regulation No. 72 of 2016 using the Centralization and Individual methods for medicines and the Floor Stock method for Medical Materials.
\end{abstract}

Keywords: Storage, Distribution, Medicine, Pharmacy Installlation Noongan District Hospital

\begin{abstract}
ABSTRAK
Pengelolaan obat merupakan salah satu segi manajemen rumah sakit yang sangat penting dalam penyediaan pelayanan kesehatan secara keseluruhan karena ketidakefisienan dan ketidaklancaran pengelolaan obat akan memberi dampak negatif terhadap rumah sakit baik secara medik, sosial, maupun secara ekonomi. Penelitian ini bertujuan untuk mengevaluasi penyimpanan dan pendistribusian obat sesuai dengan Peraturan Menteri Kesehatan No. 72 Tahun 2016 di Instalasi Farmasi RSUD Noongan menggunakan metode deskriptif dengan pendekatan retrospektif dan prospektif. Hasil penelitian menunjukkan bahwa sistem penyimpanan obat di Instalasi Farmasi RSUD Noongan secara keseluruhan belum sesuai dengan Peraturan Menteri Kesehatan No. 72 Tahun 2016 seperti, gudang yang tidak terlalu luas untuk menyimpan semua persediaan obat, tidak adanya pengatur kelembaban, tidak adanya papan alas dan obat diletakkan langsung dilantai, sedangkan pada proses pendistribusian obat telah sesuai dengan Peraturan Menteri Kesehatan No. 72 Tahun 2016 dengan menggunakan metode Sentralisasi dan Perorangan untuk obat-obatan dan metode Floor Stock untuk Bahan Medis Habis Pakai.
\end{abstract}

Kata Kunci : Penyimpanan, Pendistribusian, Obat, Instalasi Farmasi RSUD Noongan 


\section{PENDAHULUAN}

Pengelolaan obat merupakan segi manajemen rumah sakit yang sangat penting dalam penyediaan pelayanan kesehatan secara keseluruhan karena ketidakefisienan dan ketidaklancaran pengelolaan obat akan memberi dampak negatif terhadap rumah sakit baik secara medic, social maupun secara ekonomi. Instalasi Farmasi Rumah Sakit adalah salah satu unit di rumah sakit yang bertugas dan bertanggung jawab sepenuhnya pada pengelolaan semua aspek yang berkaitan dengan obat atau perbekalan kesehatan yang beredar dan digunakan di rumah sakit (Siregar dan Amelia, 2003).

Penyimpanan obat merupakan proses mulai dari penerimaan obat, penyimpanan obat dan mengirimkan obat ke unit pelayanan di rumah sakit. Tujuan utama penyimpanan obat adalah mempertahankan mutu obat dari kerusakan akibat penyimpanan yang tidak baik serta untuk memudahkan pencarian dan pengawasan obat-obatan (Azis, dkk., 2005).

Penelitian yang dilakukan oleh Al-Hijrah dkk (2013) tentang pengelolaan obat di Puskesmas Mandai, Kabupaten Maros tahun 2013 menunjukkan bahwa pengelolaan obat yang terkait perencanaan dan pendistribusian obat sudah memenuhi standar pengelolaan obat di puskesmas, tetapi pengadaan dan penyimpanan obat kurang baik dan tidak sesuai dengan pedoman pengelolaan obat yang ada. Penelitian lain dilakukan oleh Puslitbang Biomedis dan Farmasi (2006) diketahui masih banyak gudang penyimpanan obat di puskesmas dan rumah sakit di Indonesia yang kurang memenuhi persyaratan seperti tidak menggunakan sistem alfabetis dalam penataannya, tidak menggunakan sistem FIFO atau FEFO dan penggunaan kartu stok yang belum memadai.

Pengamatan awal didapatkan beberapa permasalahan pada sistem penyimpanan dan pendistribusian obat pada instalasi farmasi diantaranya obat yang terdapat digudang tidak tertata dengan baik dan masih banyak lagi yang harus diperhatikan. Sebagai rumah sakit yang memiliki misi memberikan pelayanan kesehatan dengan cepat dan tepat, RSUD Noongan seharusnya mampu menjaga kualitas pelayanan kesehatan termasuk didalamnya pelayanan kefarmasian. Berdasarkan pengamatan tersebut, maka peneliti telah melakukan penelitian tentang evaluasi sistem penyimpanan dan pendistribusian di RSUD Noongan, Kabupaten Minahasa, Provinsi Sulawesi Utara.

\section{METODE PENELITIAN}

\section{Waktu dan Tempat Penelitian}

Penelitian dilaksanakan dari bulan Juli 2016 sampai bulan Agustus 2017 di Instalasi Farmasi RSUD Noongan, Kabupaten Minahasa, Provinsi Sulawesi Utara.

\section{Jenis Penelitian}

Penelitian ini menggunakan metode deskriptif dengan pendekatan retrospekstif dan prospektif melalui pengamatan langsung pada sistem yang sedang berjalan disertai wawancara dengan informan yang terlibat dalam pelaksanaan manajemen penyimpanan dan pendistribusian perbekalan farmasi di Instalasi Farmasi RSUD Noongan, Kabupaten Minahasa, Provinsi Sulawesi Utara.

\section{Metode Pengumpulan Data}


Metode pengumpulan data yang digunakan ialah observasi, wawancara dan dokumentasi.

\section{Alat dan Bahan}

Alat yang digunakan dalam penelitian ini ialah alat tulis menulis untuk mencatat hasil observasi dan wawancara serta kamera sebagai dokumentasi.

Bahan yang digunakan berupa data primer dan data sekunder penyimpanan dan distribusi obat di Instalasi Farmasi RSUD Noongan, Kabupaten Minahasa, Provinsi Sulawesi Utara. Data primer merupakan data Pengelolaan Perbekalan Farmasi Rumah Sakit dan Peraturan Menteri Kesehatan RI Nomor 72 Tahun 2016.

\begin{tabular}{lc|c|c|c}
\hline No & Variabel Evaluasi & \multicolumn{2}{|c|}{ Hasil } & \multirow{2}{*}{ Keterangan } \\
\cline { 3 - 3 } & & Ya & Tidak & \\
\hline 1. & $\begin{array}{l}\text { Gudang penyimpanan obat } \\
\text { terpisah dari instalasi pelayanan } \\
\text { (apotek) }\end{array}$ & $\checkmark$ & \\
\end{tabular}

2. Gudang cukup besar untuk menyimpan semua persediaan obat dan aman untuk pergerakan petugas

3. Terdapat ruang penyimpanan obat yang terpisah dengan alat kesehatan yang didapat peneliti secara langsung melalui observasi dan hasil wawancara. Sedangkan data sekunder merupakan data yang diperoleh peneliti dari sumber yang sudah ada berupa dokumen pencatatan dan pelaporan penyimpanan dan distribusi obat.

\section{HASIL DAN PEMBAHASAN \\ Penyimpanan Obat}

Kondisi penyimpanan pada gudang obat Instalasi Farmasi RSUD Noongan dapat dilihat pada tabel 1 .

Tabel.1. Kondisi Instalasi Farmasi RSUD Noongan pada gudang obat berdasarkan Pedoman

$\checkmark \quad$ Gudang tidak terlalu luas namun di Instalasi Farmasi RSUD Noongan terdapat 4 gudang, dimana gudang utama ada 2 yaitu gudang obat-obatan dan gudang Bahan Medis Habis Pakai (BHP) sedangkan gudang yang 2 lagi gudang cadangan apabila obatobatan atau Bahan Medis Habis Pakai (BHP) tidak cukup dalam gudang utama. 
4. Atap gudang dalam keadaan baik/tidak bocor

5. Lantai dibuat dari segel/semen

6. Dinding dibuat licin

7. Gudang memiliki ventilasi

8. Gudang memiliki jendela berteralis

9. Penerangan gudang cukup

10. Adanya pengatur kelembaban

11. Terdapat ruang/lemari terpisah untuk obat yang mudah terbakar

12. Terdapat ruang/lemari untuk obat berbahaya

13. Gudang dilengkapi dengan kunci ganda

14. Tersedia thermometer ruangan

15. Tersedia rak/lemari penyimpanan obat

16. Tersedia lemari untuk penyimpanan obat narkotika dan psikotropika

17. Tersedia lemari pendingin

18. Tersedia rak atau lemari untuk obat kadaluarsa

19. Tersedia alat bantu pemindah obat dalam gudang

20. Tersedia kartu stok untuk memberi keterangan
Kunci gudang ada pada Koordinator Instalasi Farmasi Rumah Sakit (Apoteker) dan petugas gudang 
21. Tersedia papan alas untuk barang

22. Tersedia AC/pendingin ruangan

23. Tersedia keterangan obat berbahaya

24. Tersedia keterangan obat mudah terbakar

Penyimpanan obat di RSUD Noongan ditempatkan pada unit gudang farmasi dan apotek rumah sakit Noongan. Instalasi Farmasi RSUD Noongan memiliki luas 48 $\mathrm{m}^{2}$ yang terdiri dari Instalasi Pelayanan (Apotek), gudang obat, gudang bahan habis pakai (BHP), ruang administrasi dan ruang Kepala Instalasi Farmasi. Instalasi Farmasi RSUD Noongan terdapat 2 gudang utama yaitu gudang Bahan Habis Pakai (BHP) dan gudang obat-obatan baik tablet, kapsul, sirup dan obat-obatan lainnya. Ukuran dari gudang farmasi di RSUD Noongan tidak terlalu besar, memiliki atap, dinding dan berventilasi.

Sistem pengaturan obat di gudang maupun di instalasi pelayanan (Apotek) RSUD Noongan disusun secara alfabetis, golongan dan menggunakan prinsip FIFO/FEFO. Penyimpanan obat disimpan dirak-rak terbuka, khusus pada narkotika dan psikotropika disimpan pada lemari tertutup, dan vaksin disimpan dilemari es.

Sarana gudang penyimpanan obat yang disediakan oleh manajemen RSUD Noongan berdasarkan hasil observasi terdiri dari dua ruangan gedung yaitu gudang BHP dan gudang obat dengan luas masing-masing ruangan $3 \times 4 \mathrm{~m}^{2}$. Gudang cukup besar untuk menyimpan semua persediaan obat dan aman untuk pergerakan petugas. Gudang
Karena udara di Noongan yang dingin jadi tidak diperlukan AC.

$\checkmark \quad$ Tidak ada namun sudah disendirikan

harus cukup luas agar petugas gudang dapat bergerak secara bebas untuk mengambil maupun mengatur obat yang masuk maupunn keluar. Gudang yang sempit dapat mengakibatkan petugas gudang sulit mengatur dan mengambil obat.

Berdasarkan (Anonim, 2010) menyebutkan bahwa adapun sarana yang minimal sebaiknya tersedia adalah gudang dengan luas $3 \times 4 \mathrm{~m}^{2}$ selain luas gudang, keadaan didalam gudang farmasi RSUD Noongan juga dalam keadaan baik diantaranya atap gudang tidak bocor. Hal ini harus diperhatikan karena di dalam Gudang terdapat beberapa sediaan yang jika terkena air/basah dapat mengurangi mutu dari sediaan tersebut contohnya kapsul dan tablet kedua sediaan ini apabila terkena air/basah dapat meleleh, lengket, dan rusak oleh sebab itu, atap gudang diharuskan dalam keadaan baik dan tidak bocor agar dapat menghindari rusaknya mutu dari obat yang dapat rusak jika terkena air.

Dalam penyimpanan obat diharuskan menyediakan kartu stok untuk mencatat mutasi obat (penerimaan, pengeluaran, hilang/rusak dan kadaluarsa).

Penggunaan kartu stok yang masih secara manual merupakan salah satu kekurangan prasarana di gudang Instalasi Farmasi RSUD Noongan. Kartu stok yang masih 
dilakukan secara manual sangat rentan oleh kesalahan dalam melakukan pencatatan, terlebih jika obat yang harus dicatat kartu stok cukup banyak. Dengan adanya kartu stok dapaat memudahkan petugas gudang untuk mengetahui dengan cepat jumlah persediaan obat.

Tabel.2. Prosedur penyimpanan obat Pedoman Pengelolaan Perbekalan Farmasi Rumah Sakit dan Peraturan Menteri Kesehatan RI Nomor 72 Tahun 2016.

\begin{tabular}{|c|c|c|c|c|}
\hline \multirow[t]{2}{*}{ No. } & \multirow[t]{2}{*}{ Variabel evaluasi } & \multicolumn{2}{|c|}{ Hasil } & \multirow[t]{2}{*}{ Keterangan } \\
\hline & & $\mathrm{Ya}$ & Tidak & \\
\hline 1. & $\begin{array}{l}\text { Penyimpanan obat disimpan } \\
\text { dalam gudang ruangan khusus } \\
\text { yang tidak digabung dengan } \\
\text { peralatan lain. }\end{array}$ & $\checkmark$ & & \\
\hline 2. & Obat diletakkan diatas rak/lemari & $\checkmark$ & & \\
\hline 3. & $\begin{array}{l}\text { Obat tidak diletakkan langsung } \\
\text { dilantai }\end{array}$ & & $\checkmark$ & \\
\hline 4. & $\begin{array}{l}\text { Penyimpanan LASA tidak } \\
\text { ditempatkan berdekatan dan } \\
\text { harus diberi penandaan khusus }\end{array}$ & $\checkmark$ & & \\
\hline 5. & $\begin{array}{l}\text { Obat tidak diletakkan menempel } \\
\text { didinding }\end{array}$ & $\checkmark$ & & \\
\hline 6. & $\begin{array}{l}\text { Penyimpanan obat sesuai metode } \\
\text { FIFO }\end{array}$ & $\checkmark$ & & \\
\hline 7. & $\begin{array}{l}\text { Penyimpanan obat sesuai metode } \\
\text { FEFO }\end{array}$ & $\checkmark$ & & \\
\hline 8. & $\begin{array}{l}\text { Penyimpanan obat berdasarkan } \\
\text { jenis obat }\end{array}$ & $\checkmark$ & & \\
\hline 9. & $\begin{array}{l}\text { Penyimpanan obat berdasarkan } \\
\text { bentuk sediaan }\end{array}$ & $\checkmark$ & & \\
\hline 10. & $\begin{array}{l}\text { Penyimpanan obat berdasarkan } \\
\text { abjad }\end{array}$ & $\checkmark$ & & \\
\hline 11. & $\begin{array}{l}\text { Penyimpanan obat berdasarkan } \\
\text { kelas terapi }\end{array}$ & & $\checkmark$ & \\
\hline
\end{tabular}


12. Obat yang rusak diletakkan terpisah dengan obat yang masih baik

13. Obat yang expire diletakkan terpisah dengan obat yang masih baik

14. Obat golongan narkotika dan psikotropika diletakkan dalam lemari

15. Lemari obat golongan narkotika dan psikotropika selalu dikunci

16. Diberikan label (penamaan) pad arak penyimpanan

Prosedur penyimpanan obat di Instalasi Farmasi RSUD Noongan hampir 80\% memenuhi ketentuan tentang standar pelayanan kefarmasian di rumah sakit yaitu penyimpanan obat disimpan dalam gudang ruangan khusus yang tidak digabung dengan peralatan lain, penyimpanan obat menggunakan metode FEFO/FIFO, obat diletakkan diatas lemari/rak, penyimpanan
LASA, rusak dan expire (kadaluarsa) tidak ditempatkan berdekatan dan diberi tanda, obat golongan narkotika dan psikotropika disimpan dalam lemari terkunci.

\section{Pendistribusian Obat}

Pendistribusian obat di Instalasi RSUD Noongan, Kabupaten Minahasa, Provinsi Sulawesi Utara terjadi dalam beberapa tahap sampai ke tangan pasien.

Tabel.3. Pendistribusian obat Instalasi Famasi RSUD Noongan, Kabupaten Minahasa, Provinsi Sulawesi Utara Berdasarkan Peraturan Menteri Kesehatan Nomor 72 Tahun 2016.

\begin{tabular}{|c|c|c|c|c|}
\hline \multirow[t]{2}{*}{ No. } & \multirow[t]{2}{*}{ Standar Pelayanan di Rumah Sakit } & \multicolumn{2}{|c|}{ Hasil } & \multirow[t]{2}{*}{ Keterangan } \\
\hline & & $\mathrm{Ya}$ & Tidak & \\
\hline 1. & Menggunakan metode Sentralisasi & $\checkmark$ & & \\
\hline 2 . & Menggunakan metode Desentralisasi & & $\checkmark$ & \\
\hline 3. & Menggunakan metode Perorangan & $\checkmark$ & & \\
\hline 4. & Menggunakan metode Floor Stock & $\checkmark$ & & $\begin{array}{l}\text { Hanya untuk } \\
\text { Bahan Medis } \\
\text { Pakai }\end{array}$ \\
\hline
\end{tabular}


5. Menggunakan metode One Day Dose Dispensing

6. Menggunakan metode Kombinasi

Sistem distribusi obat pada pasien rawat inap dan rawat jalan berdasarkan hasil penelitian menggunakan metode sentralisasi, dimana sistem ini dipusatkan pada suatu tempat di Instalasi Farmasi (unit/bagian distribusi perbekalan farmasi) tepatnya di instalasi pelayanan (Apotek). Sistem distribusi sentralisasi merupakan sistem distribusi dimana obat secara langsung diberikan oleh petugas Instalasi Farmasi kepada pasien atau keluarga pasien. Instalasi Farmasi RSUD Noongan sebenarnya menggunakan sistem distribusi One Day Dose Dispensing untuk pasien rawat inap menurut SOP, namun sistem tersebut belum terlaksana dengan baik dikarenakan sumber daya manusia yang tidak mencukupi.

Perbekalan farmasi yang didistribusikan ke unit-unit rumah sakit hanya Bahan Medis Habis Pakai dengan menggunakan sistem Floor Stock, dimana setiap barang yang keluar dicatat pada buku anfra. Sistem floor stock merupakan sistem distribusi persediaan lengkap diruangan yang diambil dan disiapkan oleh perawat di ruang perawatan. Pendistribusian Bahan Medis Habis Pakai ke unit-unit rumah sakit diambil oleh perawat berdasarkan lembar permintaan yang telah ditandatangani oleh bagian yang menyetujui, mengetahui, pengurus barang dan penerima. Pendistribusian Bahan Medis Habis Pakai di RSUD Noongan umumnya dilakukan oleh perawat dikarenakan kurangnya tenaga farmasi di rumah sakit, sehingga pendistribusian dari Instalasi Farmasi sampai kepada pasien dilakukan sepenuhnya oleh perawat. Instalasi Farmasi
RSUD Noongan hanya mendistribusikan obat kepada pasien yang melakukan pengobatan di RSUD Noongan dan tidak diberikan untuk pasien/pembeli yang melakukan pengobatan di luar RSUD Noongan hal ini bertujuan untuk pengendalian obat di rumah sakit.

\section{KESIMPULAN}

1. Sistem penyimpanan obat di RSUD Noongan, Kabupaten Minahasa, Provinsi Sulawesi Utara secara keseluruhan belum memenuhi Standar Penyimpanan berdasarkan Pedoman Pengelolaan Perbekalan Farmasi Rumah Sakit dan Peraturan Menteri Kesehatan RI Nomor 72 Tahun (2016) seperti, gudang yang tidak terlalu luas untuk menyimpan semua persediaan obat, tidak adanya pengatur kelembaban, tidak adanya papan alas dan obat diletakkan langsung dilantai, tidak ada keterangan untuk obat mudah terbakar, dan penyimpanan obat yang tidak disimpan berdasarkan kelas terapi.

2. Pendistribusian obat di Instalasi Farmasi RSUD Noongan, Kabupaten Minahasa, Provinsi Sulawesi Utara telah sesuai dengan Standar Pelayanan Farmasi Rumah Sakit berdasarkan Peraturan Menteri Kesehatan Nomor 72 Tahun (2016) dan Standar Pelayanan Operasional Prosedur Dsitribusi Obat RSUD Noongan, Kabupaten Minahasa, Provinsi Sulawesi Utara seperti telah menggunakan metode Sentralisasi dan Perorangan untuk obat-obatan, dan 
metode Floor Stock untuk Bahan Medis

Habis Pakai.

\section{DAFTAR PUSTAKA}

Al Hijrah. 2013. Studi Tentang Pengelolaan

Obat di Puskesmas Mandai

Kabupaten Maros Tahun 2013.

Skripsi. Fakultas Kesehatan

Masyarakat. Universitas Hassanudin.

Makassar.

Anonim. 2010. Departemen Kesehatan

Republik Indonesia. Peraturan

Menteri Kesehatan Republik

Indonesia Nomor 340 Tahun 2010

Tentang Klasifikasi Rumah Sakit.

Jakarta.

Anonim. 2016. Departemen Keesehatan

Republik Indonesia. Peraturan

Menteri Kesehatan Republik

Indonesia Nomor 3 Tahun 2016

Tentang Pedoman Pengelolaan

Perbekalan Farmasi Rumah Sakit.

Jakarta.

Azis, S., Herman, M. J., dan Mun'im, A. 2005. Kemampuan Petugas Menggunakan Pedoman Evaluasi Pengelolaan dan Pembiayaan Obat. Majalah Ilmu Kefarmasian, Vol. II, No. 2, Agustus 2005, 24.

Puslitbang Biomedis. 2006. Evaluasi Manajemen Sistem Penyimpanan Obat di Puskesmas dan Rumah Sakit Daerah Jabodetabek. Jakarta.

Siregar, C. J. P., dan Amalia, L. 2003. Farmasi Rumah Sakit, Teori dan Penerapan. Jakarta : Penerbit Buku Kedokteran EGC. 